IP Periodica Polytechnica Chemical Engineering

61(2), pp. 117-127, 2017

https://doi.org/10.3311/PPch.8611

Creative Commons Attribution (i)

RESEARCH ARTICLE

\section{Experimental Investigation and CFD Simulation of Top Spray Fluidized Bed Coating System}

\author{
Seyed Hadi Seyedin ${ }^{1}$, Mehdi Ardjmand ${ }^{2 *}$, Ali Akbar Safekordi ${ }^{1}$, \\ Shahram Raygan ${ }^{3}$
}

Received 25 September 2015; accepted after revision 29 December 2015

\begin{abstract}
Experimentally investigated in this work is the hydrodynamics of particulates motion in a cylindrical fluidized bed equipped with a pneumatic nozzle jet flow. Subsequently, the computational fluid dynamics (CFD) is combined with the Eulerian formulation of multiphase flow to describe the hydrodynamics of particulates motion. Similar to free spray jet velocity profile, the velocity profile of output gas from nozzle is obtained based on the Schlichting equation. Particle trajectories, time dependent fluidization height, gas and solid particles velocity distributions and the fluidization height distribution of particles in different radial positions within the bed have been also considered in the course of experimental and modeling studies. The comparison between the predicted and experimental height of fluidized bed indicates a good agreement between simulation results and experimental data.
\end{abstract}

\section{Keyword}

CFD, Eulerian model, Laminar flow, Fluidized bed, Hydrodynamics

\footnotetext{
${ }^{1}$ Department of Chemical Engineering, Science and Research Branch, Islamic Azad University, Tehran, Iran

${ }^{2}$ Department of Chemical Engineering, South Tehran Branch, Islamic Azad University, Tehran, Iran

${ }^{3}$ School of Metallurgy and Materials Engineering, College of Engineering, University of Tehran, Tehran, Iran

${ }^{*}$ Corresponding author, e-mail: m_ardjmand@azad.ac.ir
}

\section{Introduction}

Fluid bed technology is a common step undertaken in the course of processes used in chemical, agricultural, pharmaceutical and food industries. Coating of solid particles is used to achieve a variety of functions such as controlled release of drugs, protecting a core against external conditions, taste or odour masking and easier powder handling $[1,2]$. In addition, fluidized bed coating technique has been used in drug delivery systems [3]. There are different fluidized bed coating systems: top spray, tangential spray, bottom spray and Wurster systems. The coating of high quality particles is often done in a circulating fluidized bed system (similar to Wurster system). In these systems, a cylinder (draft tube) of appropriate size is placed on the centre of the bed [4].

The product quality and the process efficiency are largely determined by the spray direction, bed characteristics, and particle motion characteristics in terms of residence and circulation time $[5,6]$. Top spray fluid bed system is used for particles coating. In this process, coating material is sprayed on the particles to react with them in the bed and covers their surfaces [7]. There are two general categories of coating applications: film coating (using a wax, aqueous, latex or organic coating system) and substrate layering. In the course of applications corresponding to the second category, pellets or spherical forms of a substrate are produced, via a layering approach, in powder or liquid form (e.g., solution, suspension or emulsion), onto inert carriers such as sugar spheres [8].

Being one of the most important parameters when coated particles are concerned, coating uniformity plays an important role in coating process. It is directly resulted from system design, process type and product variables [9]. Uniform distribution of the coat in fluidized bed depends on the type of coating liquid, coated particles' size and the type, fluidization air flow and nozzle spray angle. Furthermore, supersonic attrition nozzles have been used in gas-solid fluidized beds [10]. In recent years, some researches have been conducted on mathematical modelling of hydrodynamics, heat transfer and mass transfer phenomena in fluidized bed. Simulated in these investigations were the droplet deposition behaviour and 
dynamic particle populations of fluid bed in spray granulation process $[11,12]$.

Although many approaches such as black box modelling, population balance modelling, lumped region models and combined thermodynamic and population balance model [13], have been used for modelling fluidized bed coating, but limited researchers applied CFD model. CFD model has the advantage of being case independent. When tuned for a particular range of conditions, CFD model can produce predictions, for conditions other than this range, which are more likely to be accurate in comparison with those of other models. Also, CFD model can evaluate the effect of system geometry (such as design of baffle and inner pipe in fluidized bed) on coating efficiency [14]. Fluidized bed coating process consists of three major steps including fluidizing solid particles, atomizing coating solution on the bed of fluidized particles, and drying the coated particles to evaporate the solvent out of coating solution [15]. The atomized droplets consist of a solute, acting as a covering layer, and a solvent in which coating material is solved or with which coating material forms a slurry solution. Once came in contact with solid particles, liquid droplets spread over the surface of the particles before fluidizing gas can evaporates the solvent leaving a layer of coating material on particles surface. Particles usually grow via two mechanisms: (1) the agglomeration of fine particles due to liquid bridging between two or more smaller particles; (2) the growth of coating layer on a particle. The first process occurs when the liquid bridge is strong enough to hold particles together. The fluidizing air supplies required evaporative capacity to remove the remaining solvent on the surface of the fluidized particles. When liquid binders or dissolved coating material are added to a fluidized bed, two different states of particle growth are possible, depending on the mass transfer of binder to the fluid particles and the evaporation capacity within the bed [16]. In some cases, powders are fluidized with a binder solution or suspension sprayed on to the fluidized particles to create liquid bridges leading the powder to be agglomerated [17]. When wet particles collide with each other, a wet bridge forms between them. Depending on the liquid bridge strength and kinetic energy of the colliding particles, these bridges may persist beyond the drying point where dry agglomerates form [18, 19]. This type of particle growth is called "agglomeration". Fluid bed spray agglomeration is similar to the fluid bed granulation. However, when fluidized beds operate under drying conditions, evaporation capacity of the bed increases sufficiently drying the particle surface before collision thus terminating the formation of liquid bridges [20].

The researches by Smith and Nienow [21] and Maronga and Wnukowski [22, 23] have shown that particles are uniformly wet in a so-called wetting zone which is a small region in the vicinity of the spray. The repeated wetting - drying cycle of fluidized particles creates of a uniform, layered structure around individual particles; this type of particle growth is called "layering" [20]. Layering represents the preferred growth mechanism in coating applications. Dry processing conditions are required to improve the layered growth mechanism. Under such conditions, however, considering the fact that the coating solution is sprayed counter currently with the fluidizing air, premature droplet evaporation is likely to take place before droplet can come in contact with particle surface [24].

There are numerous variables affecting a fluidized bed coating process [15]. These variables can be classified into three main categories including process variables, design variables and physical property variables (physical properties of coating material and solid particles). According to Schlünder and Link, following a trial and error approach represents the only way to determine optimum operating conditions for a fluidized bed coating process. This is because of enormous number of variables affecting fluidized bed coating process [20, 25].

CFD simulation is a useful tool for study on new equipment and process technologies such as fluidized bed, spray dryer, atomization process in nozzles and Glatt's ProCell technology. Based on computational fluid dynamics, there are two general approaches to follow in the course of two-phase modeling of fluidized beds. Known as the two-fluid model (TFM), the first approach uses CFD only. The second approach, however, is a combination of the continuum and discrete model (CCDM) achieved by coupling the discrete element method (DEM) with CFD. Encompassing more details and models for discrete element problems, DEM is seen to be more efficient in complicated simulations [26]. However, CCDM is a new technique that can simulate micro-scale behavior of fluid-particle systems [27].

In this research, some experiments have been undertaken to study hydrodynamics of particulates motion in a cylindrical fluidized bed equipped with a pneumatic nozzle jet flow. The computational fluid dynamic modeling of the particles' hydrodynamics was performed for the circulating fluidized bed. Subsequently modeled were the liquid and solid velocity contours, particle trajectories, time dependent fluidization height, solid velocity vectors and the fluidization height distribution of particles along radial direction. COMSOL Multiphysics 4.4 CFD software was used to model two-phase flow with the continuous phase being air and the dispersed phases being liquid and solid particles (granular flow). The Euler-Euler model was chosen to simulate the two-phase flow within the process chamber. Ignoring any contact or interaction between solid and liquid phases, this study considered the hydrodynamics of the process only.

\section{Experimental Setup}

Used in the present research was a top spray coating system with its schematics being shown in Fig. 1. The Plexiglas cylindrical chamber was employed for fluidized bed experiments where the bed height and diameter were $450 \mathrm{~mm}$ and $170 \mathrm{~mm}$, respectively. There was a small cylinder (draft tube) of 100 $\mathrm{mm}$ diameter and $170 \mathrm{~mm}$ height in the centre of the bed. This 
cylinder provided circular flow of particles to enhance coating process. Placed on top of the bed, a pneumatic nozzle was used to change the liquid jet into droplets by the air-generated force. Once spraying process was performed, the coated particles were dried in the bed. In each fluidization cycle, $20 \mathrm{gr}$ of micro pearl glass beads (Sovitec, Fleurus, Belgium) of d43=365 $\mu \mathrm{m}$ were used as the core material.

\subsection{System Performance}

The air flow leaves the blower and enters into the bed via the air distributer plate located in bottom of the bed. The compressed air goes into the nozzle to spray the coating liquid on the fluidized particles. During each cycle, the coating liquid is sprayed on fluidized particles before they get dried. This system is composed of the following three main parts:

1. A nozzle to spray the liquid.

2. An air distribution plate to fluidize the particles.

3. A draft tube to create the circulating flow.

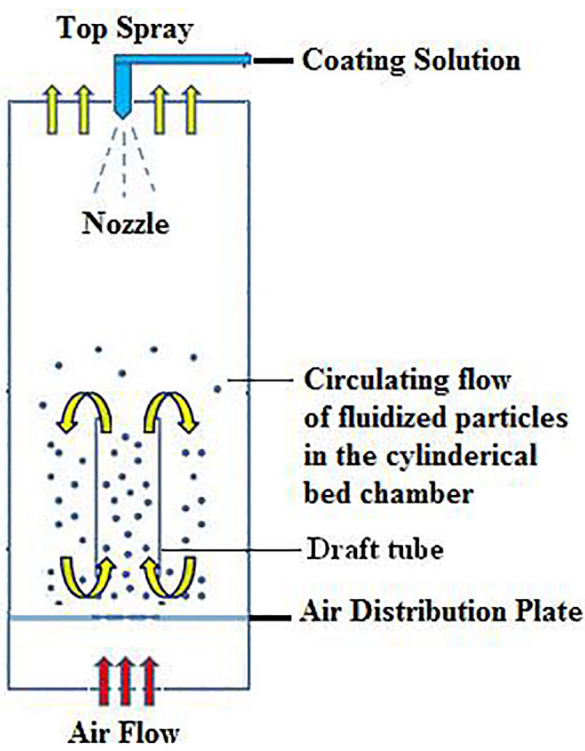

Fig. 1 Schematic drawings of a top spray fluidized bed.

\section{Mathematical Model}

The contribution of each phase into conservation equations was determined by its corresponding volume fraction. Solid particles were treated as granular flow model which was based on gas molecules motion. Considered in this study was only the hydrodynamics of solid-gas flow inside a fluidized bed in the presence of nozzle jet flow. The governing conservation equations of mass, momentum and physical models involved in the process were discretized over control volumes and solved by finite volume method. Gas-solid flow modeling was performed in Eulerian framework with gas and solid particles considered as two continuum phases penetrating into each other [26]. The continuity equation for each phase was described as:

$$
\frac{\partial\left(\alpha_{k} \rho_{k}\right)}{\partial t}+\nabla \cdot\left(\alpha_{k} \rho_{k} \vec{v}_{k}\right)=0
$$

where $\vec{v}_{k}$ and $\alpha_{k}$ denote the velocity and total volume fraction of the $k$ th phase [26]. Thus the total momentum change with time in each phase is:

$$
\frac{d(m v)}{d t}=F_{t}
$$

The momentum balance equation for gas phase is:

$$
\begin{aligned}
& \frac{\partial}{\partial t}\left(\alpha_{g} \rho_{g} \vec{v}_{g}\right)+\nabla \cdot\left(\alpha_{g} \rho_{g} \vec{v}_{g} \vec{v}_{g}\right) \\
& =-\alpha_{g} \nabla P+\nabla \overline{\bar{\tau}}_{g}+\alpha_{g} \rho_{g} g+B_{g s}\left(\vec{v}_{g}-\vec{v}_{s}\right)
\end{aligned}
$$

Obtained in terms of Reynolds stress tensor $\left(\overline{\bar{\tau}}_{g}\right)$, turbulent predictions for the continuous gas phase were determined using the standard $k-\varepsilon$ model supplemented with extra terms corresponding to interphase turbulent momentum transfer [28]. Momentum balance equation for solid phase is:

$$
\begin{aligned}
\frac{\partial}{\partial t}\left(\alpha_{s} \rho_{s} \vec{v}_{s}\right)+\nabla \cdot\left(\alpha_{s} \rho_{s} \vec{v}_{s} \vec{v}_{s}\right)= & -\alpha_{s} \nabla P-\nabla P_{s}+\nabla \overline{\bar{\tau}}_{s} \\
& +\alpha_{s} \rho_{s} g+B_{g s}\left(\vec{v}_{g}-\vec{v}_{s}\right)
\end{aligned}
$$

Equation (4) was used to constitute the solid stress tensor $\left(\overline{\bar{\tau}}_{s}\right)$ and solid pressure $\left(P_{s}\right)$ in the momentum conservation equation for the solid phase. $B_{g s}$ represents the gas-solid exchange coefficient included in the momentum conservation equation which is chosen based on the Gidaspow's drag model; this model is known to be appropriate for flows where drastic changes in the solids volume fraction occur (e.g., flows in a Wurster chamber). It has also been reported [29] that using the Gidaspow's drag model gives the best agreement between experimental and simulation data for local solids volume fractions and velocities in a fluidized bed. The interphase drag coefficient $\left(B_{g s}\right)$ is calculated according to the Gidaspow's drag model [29] using Ergun equation (Eq. (5)) for dense phase flow and the Wen and Yu model (Eq. (6)) for dilute phase flow.

$$
\begin{gathered}
B_{g s-\text { Ergun }}=150 \frac{\alpha_{s}^{2} \mu_{g}}{\alpha_{g} d_{s}^{2}}+1.75 \frac{\alpha_{s} \alpha_{g}}{d_{P}}\left|\overrightarrow{v_{s}}-\overrightarrow{v_{g}}\right|, \quad \alpha_{g}<0.8 \\
B_{g s-W e n-y u}=\frac{3}{4} C_{D} \frac{\alpha_{s} \alpha_{g} \rho_{g}}{d_{s}}\left|\overrightarrow{v_{s}}-\overrightarrow{v_{g}}\right| \alpha_{g}^{-2.65}, \quad \alpha_{g} \geq 0.8
\end{gathered}
$$

where $C_{D}$ is the drag coefficient defined as:

$$
\begin{aligned}
& C_{D}=\left[1+0.15\left(\alpha_{g} R e_{s}\right)^{0.687}\right]\left(24 / R e_{s}\right), \quad R e_{s}<1000 \\
& C_{D}=0.44, \quad R e_{s}>1000
\end{aligned}
$$

The corresponding Reynolds number to the particles is calculated by Eq. (8).

$$
R e_{s}=\frac{\rho_{g} d_{s}\left|\overrightarrow{v_{s}}-\overrightarrow{v_{g}}\right|}{\mu_{g}}
$$

The kinetic theory describing the flow of smooth, slightly inelastic spherical particles was applied. The granular temperature 
of the solid phase $\left(\Theta_{s}\right)$ was introduced as a measure of the kinetic energy of random particle motion by Eq. (9).

$$
\Theta_{s}=\frac{1}{3}\left(v_{s}^{\prime 2}\right)
$$

The granular temperature was calculated using an algebraic expression obtained from the transport equation derived by Lun et al. [30] wherein the convection and diffusion terms of the more general form of the transport equation were neglected assuming local dissipation of granular kinetic energy of the solid phase [30]. The conservation equation for granular temperature is:

$$
\begin{aligned}
& \frac{3}{2}\left[\frac{\partial}{\partial t}\left(\alpha_{s} \rho_{s} \Theta_{s}\right)+\nabla \cdot\left(\alpha_{s} \rho_{s} \Theta_{s} v_{s}\right)\right]=\left(-P_{s} \overline{\bar{I}}+\overline{\bar{\tau}}_{s}\right): \nabla \vec{v}_{s} \\
& -\nabla\left(k_{\theta s} \nabla \Theta_{s}\right)-\gamma_{\theta s}
\end{aligned}
$$

The term $\left(-P_{s} \overline{\bar{I}}+\overline{\bar{\tau}}_{s}\right): \nabla \vec{v}_{s}$ represents the generation of energy by the solid stress tensor and the term $\nabla\left(k_{\theta s} \nabla \Theta_{s}\right)$ describes the diffusive flux of granular energy. Denoting the rate of energy dissipation within the solid phase due to solid phase particle collisions [30], $\gamma_{\theta s}$ is expressed as:

$$
\gamma_{\theta s}=\frac{12\left(1-e_{s s}^{2}\right) g_{0, s s}}{d_{s} \sqrt{\pi}} \alpha_{s}^{2} \rho_{s} \Theta_{s}^{\frac{3}{2}}
$$

where $e_{s s}$ is the coefficient of restitution for particle collisions with a default value of 0.9 indicating that particles' collision is close to elastic collision, $g_{0, s s}$ represents the radial distribution function as a correction factor modifying the probability of collisions between particles as the solids fraction increases towards its maximum packing limit and can also be regarded as a non-dimensional distance between spheres.

Lun's equation [30] for $g_{0, s s}$ is as follows:

$$
g_{0, s s}=\left[1-\left(\frac{\alpha_{s}}{\alpha_{s, \max }}\right)\right]^{-2.5 \alpha_{s, \max }}
$$

For granular flows in which $\alpha_{s}<\alpha_{s, \max }$, the solid pressure is independently calculated and used for the pressure gradient term, $\nabla p s$, in the momentum conservation equation for the solid phase in Eq. (4). The solid pressure is composed of a kinetic term and a second term corresponding to particle collisions. Solid pressure is computed by Lun's equation [30] as follows:

$$
P_{s}=\alpha_{s} \rho_{s} \Theta_{s}+2 \rho_{s}\left(1+e_{s s}\right) \alpha_{s}^{2} g_{0, s s} \Theta_{s}
$$

Having shear and bulk viscosity components arising from particle momentum exchange via particle translation and collision, the solid stress tensor $\overline{\bar{\tau}}_{s}$ in Eq. (4) can be computed as follows:

$$
\overline{\bar{\tau}}_{s}=\alpha_{s} \mu_{s}\left(\nabla \vec{v}_{s}+\nabla \vec{v}_{s}^{T}\right)+\alpha_{s}\left(\lambda_{s}-\frac{2}{3} \mu_{s}\right) \nabla \overrightarrow{v_{s}} \overline{\bar{I}}
$$

where $\overline{\bar{I}}$ is the unit matrix, $\vec{v}_{s}^{T}$ is transpose of $\vec{v}_{s}, \mu_{s}$ is solid shear viscosity; accounting for resistance of the granular particles to compression and expansion, the solids bulk viscosity, $\lambda_{s}$, can be determined by Lun's equation [30].

$$
\lambda_{s}=\frac{4}{3} \alpha_{s} \rho_{s} d_{P} g_{0, s s}\left(1+e_{s s}\right) \sqrt{\frac{\Theta_{s}}{\pi}}
$$

The solid shear viscosity consists of collisional, kinetic and optional frictional terms expressed as follows:

$$
\mu_{s}=\mu_{s, c o l}+\mu_{s, k i n}+\mu_{s, f r i c}
$$

The frictional part of solid viscosity becomes important as the solid volume fraction gets close to solid packing limit $\left(\alpha_{s, \max }\right)$. The collisional and kinetic terms of solid shear viscosity were defined by Gidaspow et al. [29]:

$$
\begin{gathered}
\mu_{s, c o l}=\frac{4}{5} \alpha_{s} \rho_{s} d_{s} g_{0, s s}\left(1+e_{s s}\right) \sqrt{\frac{\Theta_{s}}{\pi}} \\
\mu_{s, k i n}=\frac{10 d_{s} \rho_{s} \sqrt{\Theta_{s} \pi}}{96 \alpha_{s}\left(1+e_{s s}\right) g_{0, s s}} \\
{\left[1+\frac{4}{5} g_{0, s s} \alpha_{s}\left(1+e_{s s}\right)\right]^{2}}
\end{gathered}
$$

\section{Laminar Model}

The laminar flow Euler-Euler model was used to model laminar flow of continuous gas phase. The model satisfies certain mathematical constraints of the Reynolds stresses that are consistent with the physics of laminar flows. An immediate benefit of the realizable laminar model is that it predicts the spreading rate of both planar and round jets accurately. In this section, the conservation equations for inviscid flow in an inertial (nonrotating) reference frame are presented [31]. The general form of the mass conservation equation (also known as the continuity Equation [32]) is expressed as follows:

$$
\frac{\partial \rho}{\partial t}+\nabla \cdot(\rho \vec{v})=S_{m}
$$

Being the general form of the mass conservation equation, Eq. (19) is valid for both compressible and incompressible flows. The source, $S_{m}$, is the mass added from the dispersed phase to the continuous phase (for example, due to vaporization of liquid droplets) together with any user-defined sources [31]. For 2D axisymmetric geometries, the continuity equation is given by:

$$
\frac{\partial \rho}{\partial t}+\frac{\partial}{\partial x}\left(\rho v_{x}\right)+\frac{\partial}{\partial r}\left(\rho v_{r}\right)+\frac{\rho v_{r}}{r}=S_{m}
$$

where $x$ and $r$ are axial and radial coordinates, respectively, and $v_{x}$ and $v_{r}$ are axial and radial velocities, respectively.

The momentum equation, based on the Newton's laws of motion, relates sum of the forces acting on a fluid element to its acceleration defined as the rate of change in momentum in the direction of the resultant force [31]. 
The momentum conservation equation can be written in the following form:

$$
\frac{\partial}{\partial t}(\rho \vec{v})+\nabla \cdot(\rho \vec{v} \vec{v})=-\nabla P+\rho \vec{g}+\vec{F}
$$

where $p$ is the static pressure, and $\rho \vec{g}$ and $\vec{F}$ denote gravitational and external body forces, respectively (for example, forces that arise from interaction with the dispersed phase). Also, $\vec{F}$ contains other model-dependent source terms such as porous media and user-defined sources [31]. For 2D axisymmetric geometries, the axial and radial momentum conservation equations are given by Eq. (22) and Eq. (23), respectively.

$$
\begin{aligned}
& \frac{\partial}{\partial t}\left(\rho v_{x}\right)+\frac{1}{r} \frac{\partial}{\partial x}\left(r \rho v_{x} v_{x}\right)+\frac{1}{r} \frac{\partial}{\partial r}\left(r \rho v_{r} v_{x}\right)=-\frac{\partial p}{\partial x} \\
& +\frac{1}{r} \frac{\partial}{\partial x}\left[r \mu\left(2 \frac{\partial v_{x}}{\partial x}-\frac{2}{3}(\nabla \cdot \vec{v})\right)\right]+\frac{1}{r} \frac{\partial}{\partial r}\left[r \mu\left(\frac{\partial v_{x}}{\partial r}+\frac{\partial v_{r}}{\partial x}\right)\right]+F_{x}
\end{aligned}
$$

and

$$
\begin{aligned}
& \frac{\partial}{\partial t}\left(\rho v_{r}\right)+\frac{1}{r} \frac{\partial}{\partial x}\left(r \rho v_{x} v_{r}\right)+\frac{1}{r} \frac{\partial}{\partial r}\left(r \rho v_{r} v_{r}\right)=-\frac{\partial p}{\partial r} \\
& \frac{1}{r} \frac{\partial}{\partial x}\left[r \mu\left(\frac{\partial v_{x}}{\partial r}+\frac{\partial v_{r}}{\partial x}\right)\right]+\frac{1}{r} \frac{\partial}{\partial r}\left[r \mu\left(2 \frac{\partial v_{r}}{\partial x}-\frac{2}{3}(\nabla \cdot \vec{v})\right)\right] \\
& -2 \mu \frac{v_{r}}{r^{2}}+\frac{2}{3} \frac{\mu}{r}(\nabla \cdot \vec{v})+\rho \frac{v_{x}^{2}}{r}+F_{r}
\end{aligned}
$$

where

$$
\nabla \cdot \vec{v}=\frac{\partial v_{x}}{\partial x}+\frac{\partial v_{r}}{\partial r}+\frac{v_{r}}{r}
$$

Based on the first law of thermodynamics, the internal energy gained by a system must be equal to the heat absorbed by the system minus work done by the system; accordingly, one can obtain general form of the equation of conservation of energy [33] as follows:

$$
\begin{aligned}
& \frac{\partial}{\partial t}(\rho E)+\nabla \cdot(\vec{v}(\rho E+p)) \\
& =-\nabla \cdot\left(k_{e f f} \nabla \cdot T-\left(\sum_{j=1}^{n} h_{j} \vec{J}_{j}\right)+\left(\overline{\bar{\tau}}_{e f f} \cdot \vec{v}\right)\right)+S_{h} a
\end{aligned}
$$

Where $k_{\text {eff }}$ is effective thermal conductivity and $J_{j}$ is the diffusion flux of species $j$. The first three terms on the right hand side of Eq. (25) represent energy transfer due to conduction, species diffusion and viscous dissipation due to effective normal shear stresses, respectively. The source term $S_{h}$ includes the heat of chemical reactions, radiation and interaction with the dispersed phase [33].

\section{Velocity Distribution of Output Air from Nozzle}

As stated by various authors $[30,34]$, the nozzle jet in a fluidized bed shows many similarities to a free axisymmetric jet, of which the gas velocity profiles are analogous to Schlichting et al. [35]. In Eqs. (27)-(28), $\bar{r}$ is the dimensionless radial coordinate with:

$$
\begin{gathered}
\bar{r}=\frac{2 r}{r_{n o z}(h)} \\
v_{a t, a x}(h, \bar{r}) \sim \frac{1}{\left(h_{n o z}-h\right)^{\frac{2}{3}}} \times \frac{1}{\left(1+0.25 \bar{r}^{2}\right)^{2}} \\
v_{a t, r d}(h, \bar{r}) \sim \frac{\bar{r}-0.25 \bar{r}^{3}}{\left(1+0.25 \bar{r}^{2}\right)^{2}}
\end{gathered}
$$

The jet radius produced by the pneumatic nozzle, $r_{n o z}(h)$, is defined as the radius where the radial gas velocity $v_{a t, r d}(h, \bar{r})$ equals to zero. $v_{a t, a x}(h, \bar{r})$ is axial gas velocity and $h_{n o z}$ is nozzle height. Figure 2 depicts the liquid jet velocity profiles produced by the pneumatic nozzle; the same is drawn numerically in Fig. 3. Equations (29) and (30) give these velocities [35].

$$
\begin{gathered}
v_{\text {axial }}=\frac{2.0619457}{\left(1+2500 r^{2}\right)^{2}} \\
v_{\text {redial }}=\frac{100 r-250000 r^{3}}{\left(1+2500 r^{2}\right)^{2}}
\end{gathered}
$$

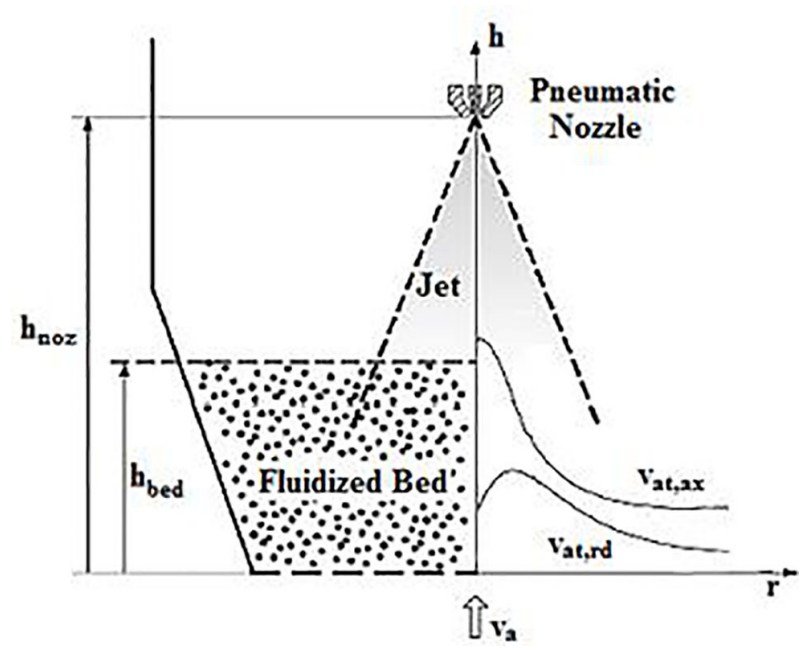

Fig. 2 Schematics of jet velocity profiles produced by the pneumatic nozzle as described by Schlichting et al. [35].

Figure 3 shows spray jet velocity distribution at different distances from the nozzle tip. One can see that the droplet concentration is high within regions near the axis of the spray; i.e., the radial distribution of the droplet velocity is in such a way that the velocity is highest at the center of the spray cone and reduces towards the edge of the spray. The liquid flow is fast in the orifice center and reduces near the orifice walls. Such reduction in liquid flow is supposed to be a result of wall effects and body friction reducing axial droplet velocity. 
The velocity reaches its maximum along spray cone center line. Since the spray jet follows a straight trajectory away from the spray cone center, the spray stream angle moves droplets farther from the straight line and the mean droplet velocity decreases in radial direction.

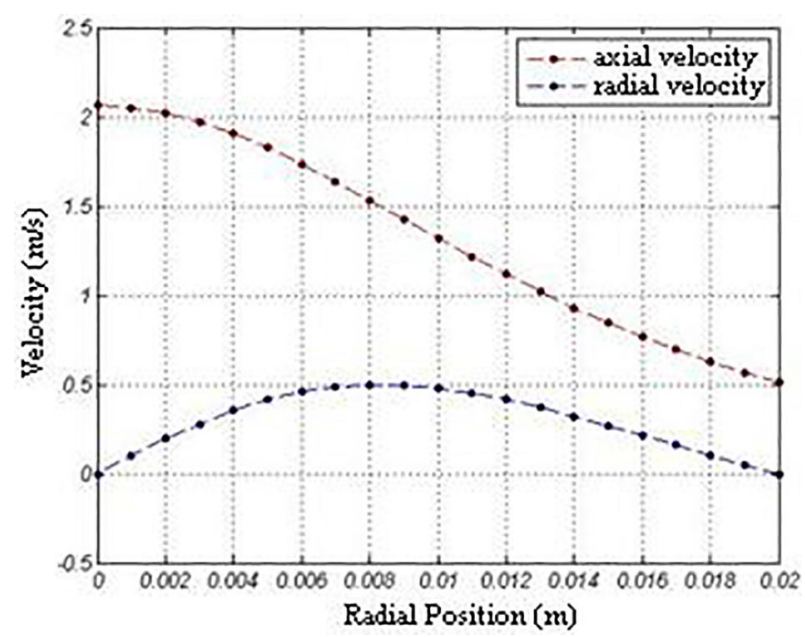

Fig. 3 Jet velocity profiles (m/s) from nozzle head.

\section{Simulation Procedure}

Hydrodynamic simulation of the bed was done by COMSOL Multiphysics software. The geometric shape was symmetrical. CFD modeling involves three main steps including creating the model geometry and grid, defining the appropriate physical models and defining the boundary and operating conditions. The generated 2D grid for the experimental geometry is depicted in Fig. 4. For the sake of simulation, the nozzle diameter was set to $1.5 \mathrm{~mm}$ with the two-phase flow consisting of a liquid phase $(70 \%)$ and air (30\%). These two phases were mixed and atomize to spray droplets. The unsteady state conditions and EulerEuler model for laminar flow were used. Starting at $t=0 \mathrm{~s}$, the solver ran for 5 seconds at $0.2 \mathrm{~s}$ time step.

\subsection{Initial and Boundary Conditions}

Initially, all dispersed particles were positioned in a packed bed section at the bottom of the column. At $t=0 \mathrm{~s}$, the packed bed height was $2 \mathrm{~cm}$, consisting of $50 \%$ particles and $50 \%$ air (i.e., volume fractions of 0.5 ), with the inlet air velocity being zero. To fluidize the bed, air was injected through the bottom with the dispersed phase volume fraction at the inlet being zero.

The boundary conditions were defined as follows:

1. Input gas velocity in bottom of the bed $=1.5 \mathrm{~m} / \mathrm{s}$.

2. Outlet gas pressure $=0$.

3. Ambient air static pressure $=1 \mathrm{~atm}$.

4. No slip condition for the continuous phase along the bed wall, and slip condition for the dispersed phase.

5. Nozzle inlet liquid velocity $=0.4 \mathrm{~m} / \mathrm{s}$.

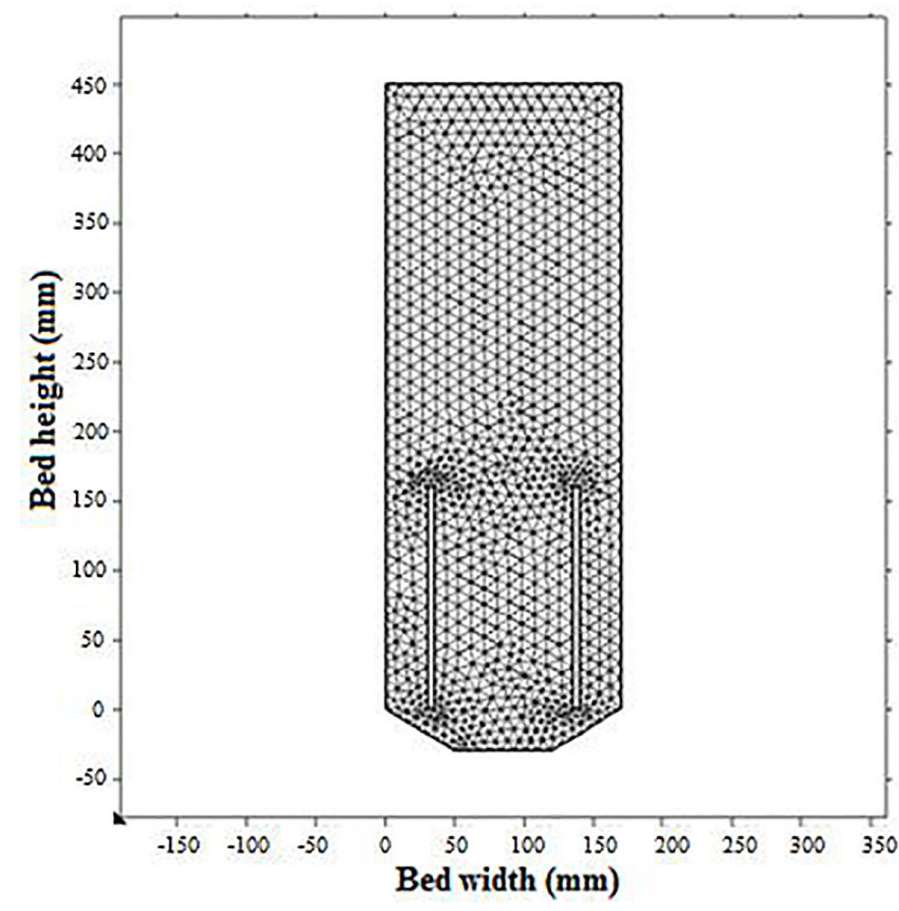

Fig. 4 Generated free triangular mesh for 2D-geometry with 54346 cells.

\section{Results and Discussion}

The characteristics of the fluidized bed system are given in Table 1. One of the measured variables was the height of fluidized particles bed which is also reported in Table 1. In this study, according to experimental results, the height of fluidized particles bed is used to validate implemented hydrodynamics model. The average height of fluidized particles bed was found to be about $90 \mathrm{~mm}$. The input gas into cylindrical bed was air at a mass flux of $1.3 \mathrm{~kg} / \mathrm{m}^{2} \mathrm{~s}$.

Table 1 Fluidized bed characteristics

\begin{tabular}{ll}
\hline Parameter & Value \\
\hline Particle density $(\mathrm{kg} / \mathrm{m} 3)$ & 2600 \\
Air density $(\mathrm{kg} / \mathrm{m} 3)$ & 1.225 \\
Air viscosity (pa.s) & $1.7894 \mathrm{E}-5$ \\
Particles diameter $(\mu \mathrm{m})$ & 365 \\
Bed height $(\mathrm{m})$ & 0.45 \\
Bed diameter $(\mathrm{m})$ & 0.17 \\
Inlet cylinder diameter $(\mathrm{m})$ & 0.07 \\
Inlet cylinder height $(\mathrm{m})$ & 0.1 \\
\hline
\end{tabular}

\subsection{Particle Velocity}

Being an important parameter in terms of coating zone residence time and circulation rate, particle velocity can lead to variations in particle coating thickness. The contours of particle velocity and droplets velocity are depicted in Fig. 5. The particles moved to top of the cylinder before exiting from the 
cylinder head; then they fell on the surface of the bed and fluidized again, creating a circulating fluid bed system.

Where air velocity increases, the distance among particles increases decreasing the particles volume fraction. Maximum velocity fluctuations at the bottom of the bed bring about maximum motion (velocity) of gas and solid phases.

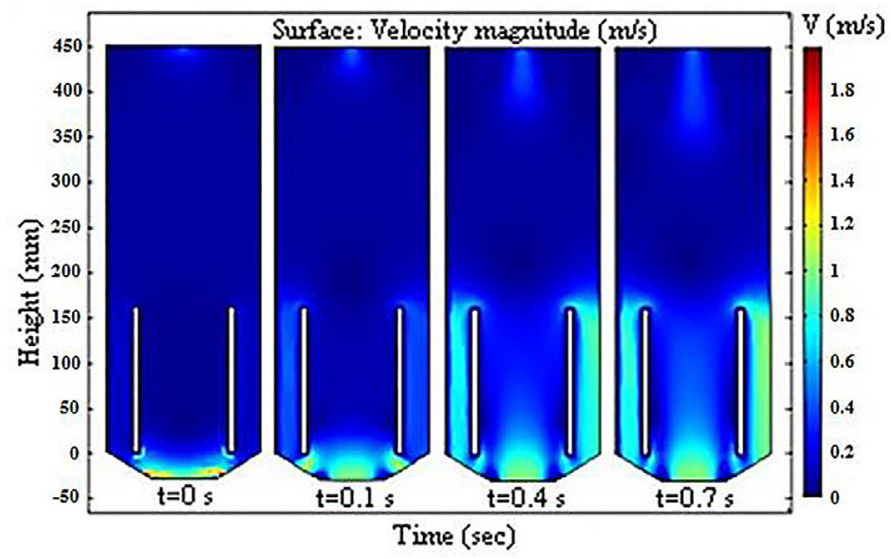

Fig. 5 Velocity contours of gas and liquid phases $(\mathrm{m} / \mathrm{s})$.

As shown in Fig. 5, Particle velocities decreases from the bottom to the top along the bed. Furthermore, as the distance from the air distributer plate increases, the gas flow velocity decreases hence reducing the exerted drag force by the gas phase to particles; the particles may then fall down by gravity force. So the cycle continues over the time. Also, based on simulation time, the spray is produced after each fluidization cycle. The maximum length of the liquid jet was generated on the top of the draft tube at the end of fluidization cycle. From the simulation results, it was evident that, due to the air velocity profile, the velocity of the particles in the middle of the draft tube was higher than that along the edges and near the wall.

The solid velocity vectors are shown in Fig. 6. As the bed height increases, the velocity of gas phase decreases because of the increased diameter of the bed, hence decreasing the drag force exerted on particles by gas phase; the particles then fell down by gravity force and the cycle was repeated again.

Figure 6 also shows the particles' movement direction within the bed. Once left the draft tube, the particles had their movement directions changed due to velocity shift and energy loss. Furthermore, some low-velocity particles near the cylinder wall recirculated back into the draft tube and started to descend towards the bottom of the chamber. This motion was in agreement with the experimental observations.

Figure 7 shows the simulation results in terms of particle velocities versus time. As gas velocity reduces in the vicinity of the walls, heavy solid phase falls down and accumulates along the walls creating pockets of high solid concentration, so that the solid phase reaches the top of the bed at around $t=0.45 \mathrm{~s}$ after which time it starts to exit the draft tube.
As shown in Fig. 7, average particle velocity decreases with time of fluidization in the bed.

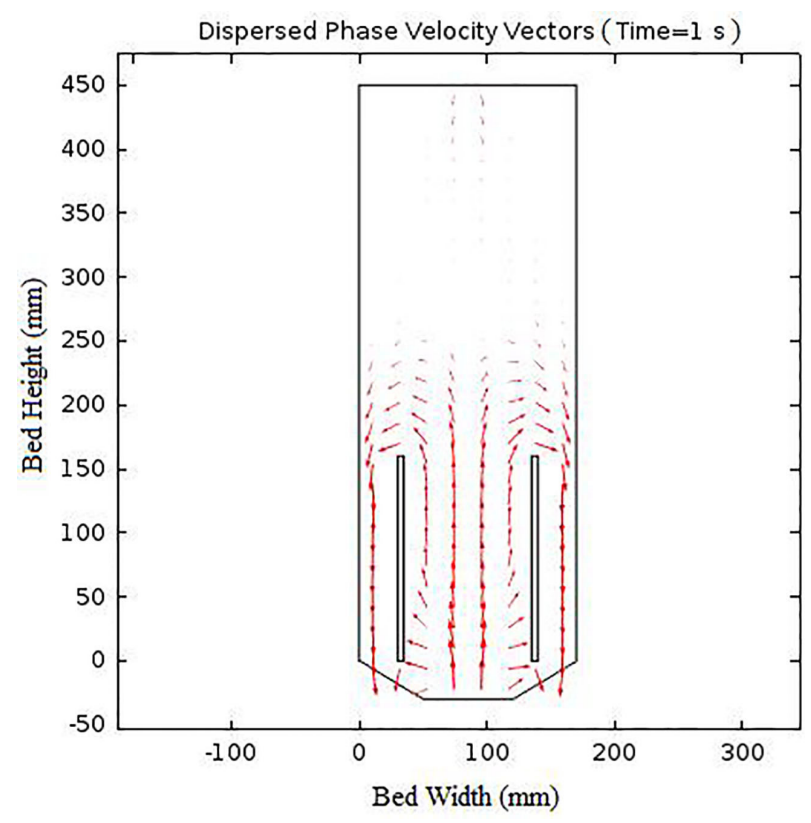

Fig. 6 Solid velocity vectors at $t=1 \mathrm{~s}$.

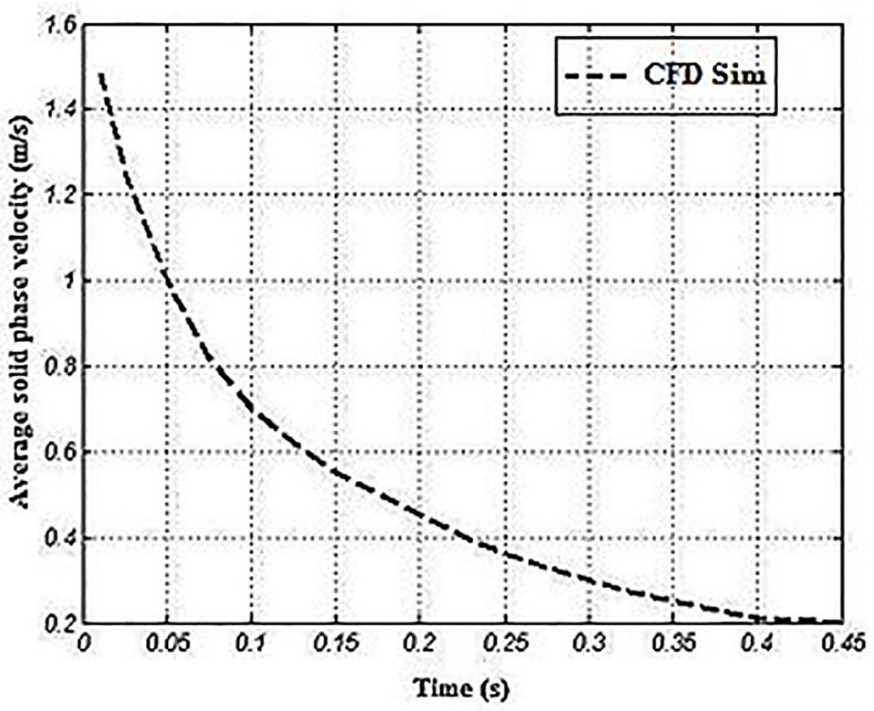

Fig. 7 CFD simulation of average solid phase velocity versus time.

Once the fluidization process begins, the buoyancy force is partly compensated with the particles weight thus drastically dropping the velocity; however, as the process proceeds, the velocity decreases slowly.

Figure 8 shows the simulation results in terms of particle velocities versus the bed height. The velocity of fluidized particles decreases as the height increases. This velocity drop is due to associated gravity force to the solid particles and energy loss of the air flow along the bed height. Velocity variations exhibit a negative slope at the bottom of the bed where particles are compressed; this slope decreases gradually as the particles expand along the bed. 


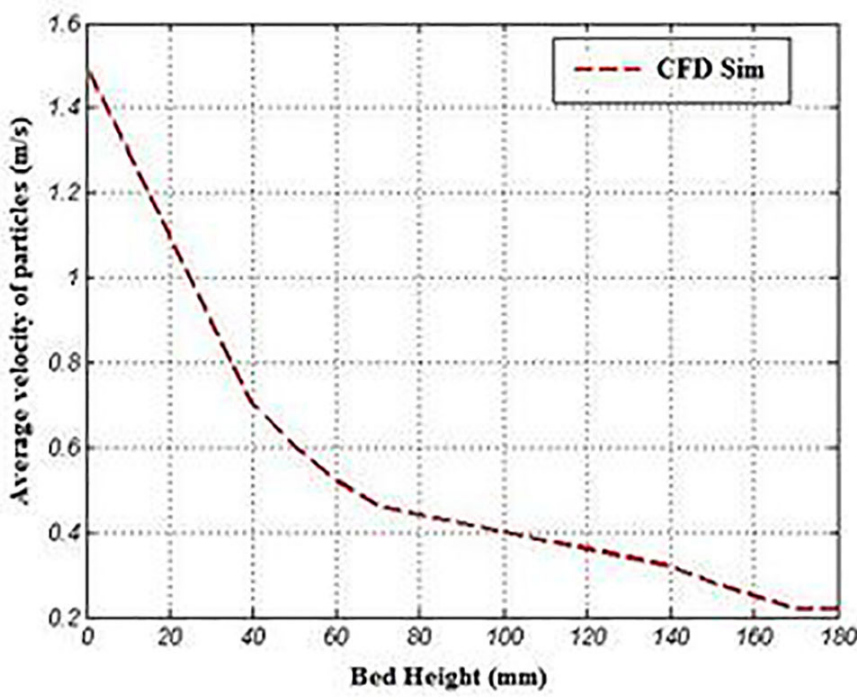

Fig. 8 CFD simulation of average velocity of particles along the bed height.

\subsection{Particle Trajectory}

The time dependant particle trajectories and fluidization heights are shown in Fig. 9. Particle trajectories show the movement direction of particles along the bed throughout fluidization time. As the time passes, the fluidization height increases.

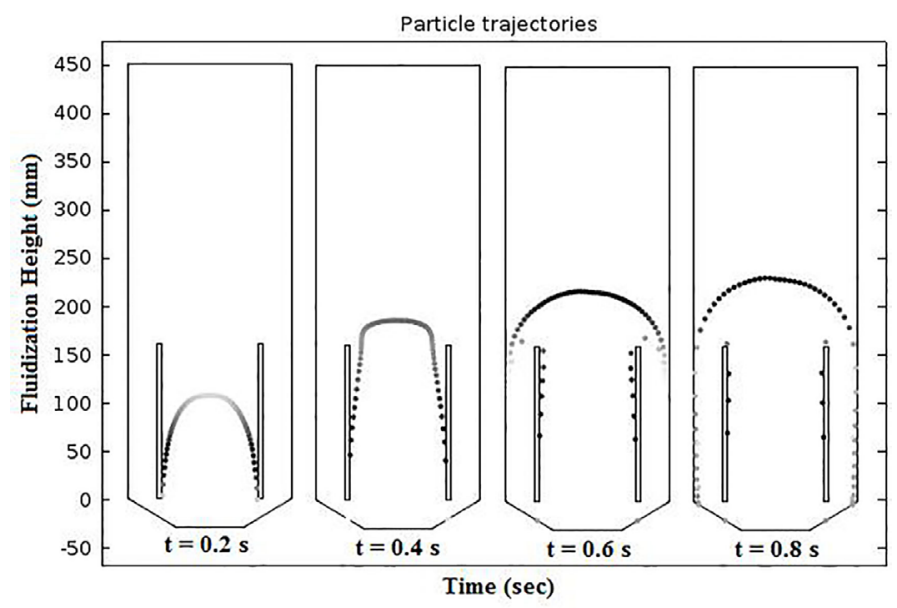

Fig. 9 Particle trajectories and fluidization heights at different times.

When the particles reach the top of the draft tube, the weight of particles overcomes fluidization air force causing the particles to fall down. Inside the cylinder, as the air flow passes through the air distributer, the particles fluidize with a parabolic shape, so that the air enters, at a reduced velocity, from the bottom of the bed regularly.

\subsection{Investigation of Fluidization Process}

Continuing with the research, glass beads were fluidized by the air flow and the extent to which particles were fluidized was investigated at different flow rates. The mean fluidization height $(\mathrm{mm})$ of particles was determined by using a digital camera in slow motion mode to capture approximate location of particles within the bed versus time. The digital images of fluidization height were then investigated via frame-by-frame image processing (using MATLAB software version R2014a) and the obtained data points were used to verify the model. Fig. 10 illustrates the variations in the height of fluidized particles. The same profile was obtained for both experimental and calculated fluidization heights. Figure 10 shows that the model simulates the reality very well prior to $t=1 \mathrm{~s}$ after which time it overestimates the reality by about $10 \%$. The particles were raised by air force, so that when air pressure dropped, the particles fell. There was a balance between the particle mass and buoyancy force exerted by the air, so that some fluctuation existed in fluidization height. At the starting time, when the air entered the bed, the particles height was equal to the minimum fluidization height, $10 \mathrm{~mm}$. Subsequently, as the air flow rate increased, the fluidization height increased lengthening the distance among particles leading the fluid bed to expand.

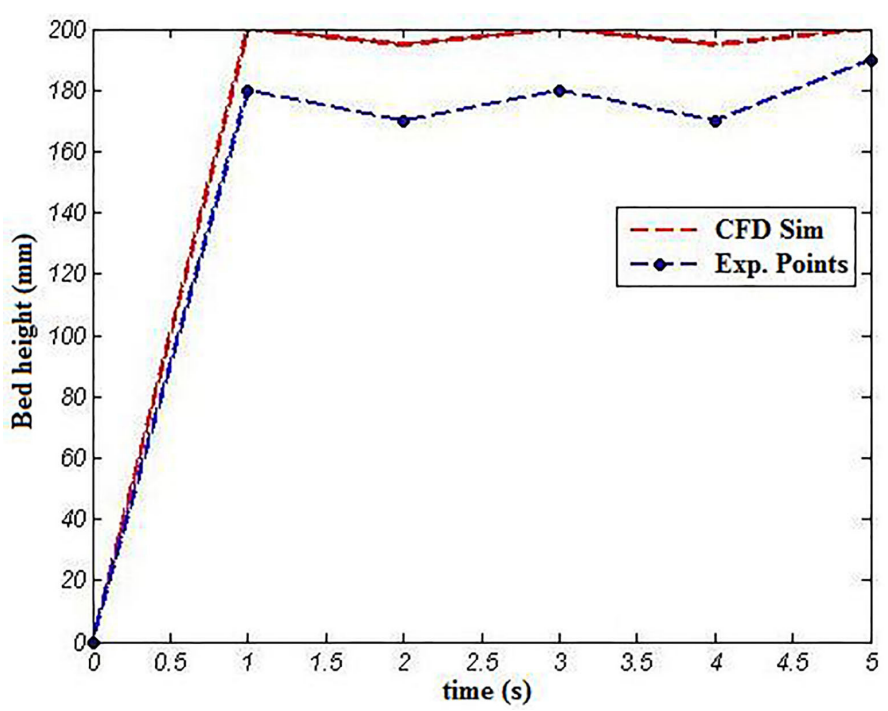

Fig. 10 Height distribution of fluidized particles versus time.

Radial fluidization height distribution of particles in the bed is shown in Fig. 11. The predicted height of fluidized particles, which represented an average value over time, was in good agreement with similar experimental measurements. The simulation results and experimental data confirmed the existence of a laminar air flow in the bed. The parabolic shape of fluidized particles stems from the fact that the particles near the wall have lower velocities (the friction between this particles and the bed wall cause them to move slower than the particles moving along the center of the bed). Also, with the air distribution plate passed, the maximum air flow rate was seen in the center of the bed with the air flow uniformly fluidizing the particles. Figure 11 indicates that the experimental data points are close to simulation results. Thus, particles' fluidization height profile produced in CFD simulation resembled the experimental case. 


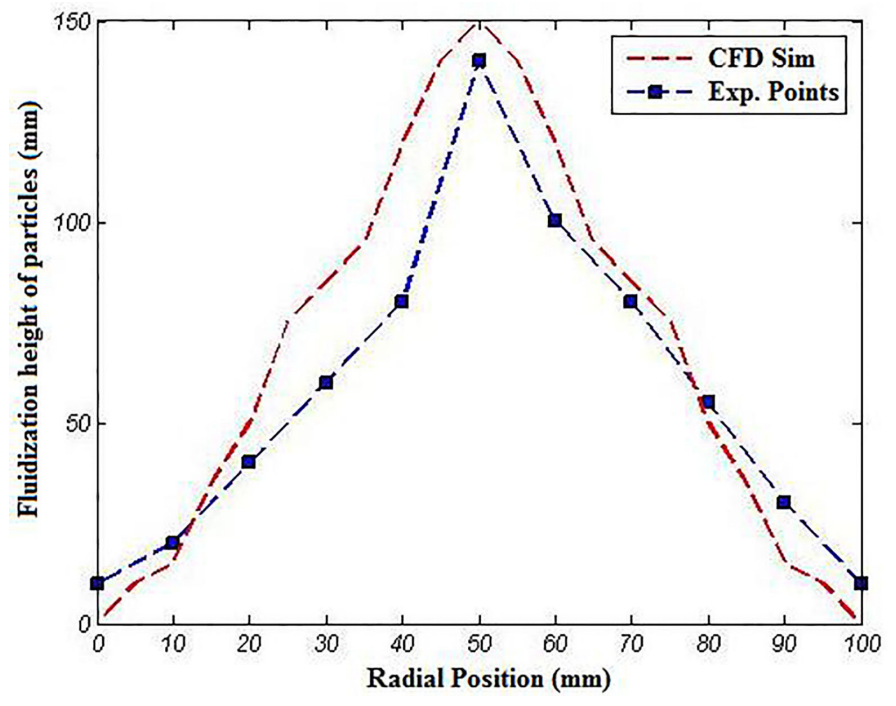

Fig. 11 Fluidization height distribution of particles versus radial position in the bed.

Using experimental data, Fig. 12 shows the variations of input air mass flux in the course of fluidization experiment. Due to pressure drop along the pipeline prior to the bed, the input air flow exhibited low oscillation per second.

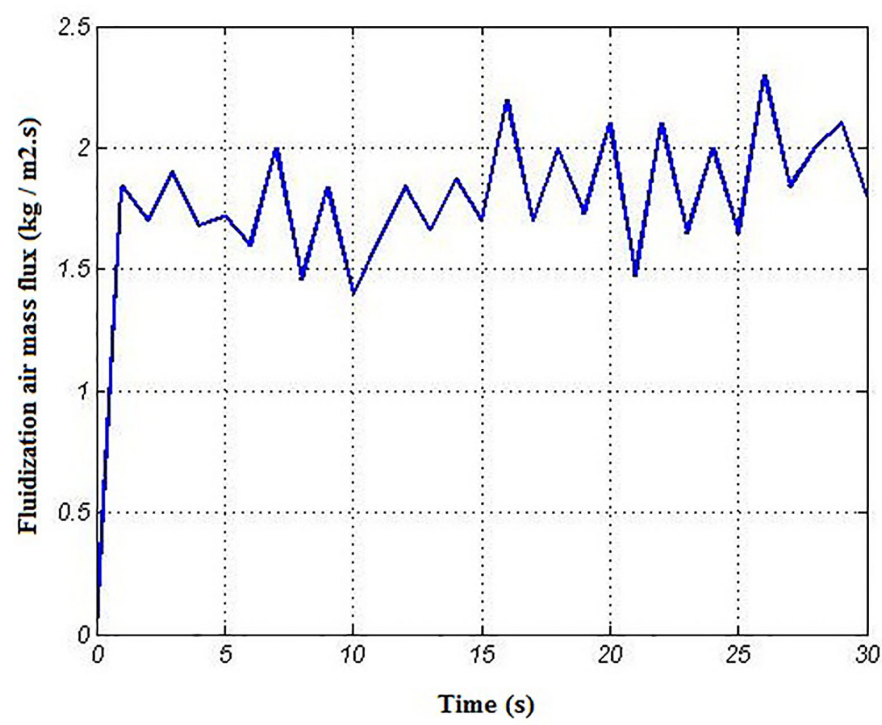

Fig. 12 Fluidization air mass flux versus time.

The novelty of this work came in the investigation of particle trajectories in the fluidized bed, type of flow regime (Laminar flow), calculation of jet velocity profiles produced by the pneumatic nozzle, and simulation of atomization process of liquid spray by Eulerian granular model.

\section{Conclusion}

In this study, the CFD modelling was undertaken, within Eulerian framework, on a 2D fluidized bed. Also the axial and radial velocity profiles of nozzle outlet air on top of the bed were simulated by means of Schlichting equation. The fluidization height and velocity of fluidized particles in the bed were studied. The predicted height of fluidized particles in the bed showed a good agreement with empirical measurements with the simulation results being well consistent with experimental data. This simulation gave a deal of valuable information on fluidization height of particles in terms of time and particle movement and velocity profiles within the fluidizing chamber for coating process in circulating fluidized bed. Being an important parameter in coating zone residence time and circulation rate and particle velocity can lead to variations in particle coating thickness. CFD results in terms of particle velocities within the bed are useful for controlling the fluidization air flow rate. A too high fluidization velocity may lead to a turbulence flow within the bed causing problems for regular circulation of particles in draft tube while inhibiting proper fluidization for coating process. We can utilize particle trajectories to select better spray angle during experiment. Also, knowing the time-out of particles fluidization cycles, one can set liquid flow rate of the nozzle, time of spraying, and the number of spray pulses in the course of coating process in such a way to not only reduce such problems as particle agglomeration due to high humidity inside the bed, but also attenuate fluctuations in fluidization height, so as to achieve more uniform fluidization while not incorporating trial and error approaches into coating experiments. The future researches can be focused on the estimation of pressure drop along the bed, calculation of continuous volume fraction and temperature variations, and simulation of heat and mass transfer in the course of coating processes in fluidized bed.

\section{Nomenclature}

$\begin{array}{ll}C_{D} & \text { drag coefficient } \\ \text { B } & \text { exchange coefficient } \\ \text { d } & \text { diameter of solid particles }(\mathrm{m}) \\ \text { E } & \text { energy }(\mathrm{j}) \\ \mathrm{F} & \text { force }(\mathrm{N}) \\ \mathrm{g} & \text { gravitational acceleration, } 9.81\left(\mathrm{~ms}^{-2}\right) \\ \mathrm{h} & \text { convection heat transfer coefficient }\left(\mathrm{Wm}^{-2} \mathrm{k}\right) \\ \mathrm{J} & \text { mass flow rate }\left(\mathrm{kgs}^{-1}\right) \\ \mathrm{m} & \text { mass }(\mathrm{kg}) \\ \mathrm{P} & \text { pressure }(\mathrm{pa}) \\ v & \text { velocity }\left(\mathrm{ms} \mathrm{s}^{-1}\right) \\ \mathrm{Re} & \text { Reynolds number } \\ \mathrm{r} & \text { radius }(\mathrm{m}) \\ \mathrm{T} & \text { temperature }(\mathrm{k})\end{array}$

\section{Greek symbols}

$\begin{array}{ll}\alpha & \text { volume fraction } \\ \mu & \text { dynamic viscosity } \\ \rho & \text { density } \\ \Theta & \text { granular temperature } \\ \overline{\bar{\tau}} & \text { Reynolds stress tensor }\end{array}$




\section{Subscripts}

$\begin{array}{ll}\mathrm{g} & \text { gas } \\ \mathrm{r} & \text { radial position or coordinate } \\ \mathrm{s} & \text { solid } \\ \mathrm{t} & \text { total }\end{array}$

\section{Acknowledgement}

This work was funded by the Metallic Material Processing Research Group (ACECR, Tehran Branch, Tehran, Iran). We would like to gratitude the technical support given by Seyed Hasan Al-Hoseini and Mohammad Golzari.

\section{References}

[1] Krupa, A., Jachowicz, R., Kurek, M., Figiel, W., Kwiecień, M. "Preparation of solid self-emulsifying drug delivery systems using magnesium aluminometasilicates and fluid-bed coating process." Powder Technology. 266, pp. 329-339. 2014. https://doi.org/10.1016/j.powtec.2014.06.043

[2] Karlsson, S., Rasmuson, A., Niklasson Björn, I., Schantz, S. "Characterization and mathematical modelling of single fluidised particle coating." Powder Technology. 207(1-3), pp. 245-256. 2011. https://doi.org/10.1016/j.powtec.2010.11.006

[3] Krupa, A., Jachowicz, R., Kurek, M., Figiel, W., Kwiecień, M. "Influence of drying conditions on layer porosity in fluidized bed spray granulation." Powder Technology. 272, pp. 120-131. 2015. https://doi.org/10.1016/j.powtec.2014.11.019

[4] Kage, H., Dohzaki, M., Ogura, H., Matsuno, Y. "Powder coating efficiency of small particles and their agglomeration in circulating fluidized bed." Korean Journal of Chemical Engineering. 16(5), pp. 630-634. 1999. https://doi.org/10.1007/bf02708143

[5] Depypere, F., Pieters, J. G., Dewettinck, K. "CFD analysis of air distribution in fluidised bed equipment." Powder Technology. 145(3), pp. 176-189. 2004. https://doi.org/10.1016/j.powtec.2004.06.005

[6] Vanderroost, M., Ronsse, F., Dewettinck, K., Pieters, J. G. "Modelling overall particle motion in fluidized beds for top-spray coating processes." Particuology Journal. 11(5), pp. 490-505. 2013. https://doi.org/10.1016/j.partic.2012.07.012

[7] Guignon, B., Duquenoy, A., Dumoulin, E. D. "Fluid bed encapsulation of particles: principles and practice." Drying Technology. 20(2), pp. 419-447. 2002. https://doi.org/10.1081/drt-120002550

[8] Evdokia, S. K., Dimitrios, M. R., Paraskevas, P. D., Nikolaos, H. C. "Optimization of the pelletization process in a fluid-bed rotor granulator using experimental design." AAPS PharmSciTech. 1(4), pp. 71-75. 2000. https://doi.org/10.1208/pt010435

[9] Cheng, X. X., Turton, R. "The prediction of variability occurring in fluidized bed coating equipment. I. The measurement of particle circulation rates in a bottom-spray fluidized bed coater." Pharmaceutical Development and Technology. 5(3), pp. 311-322. 2000. https://doi.org/10.1081/pdt-100100546

[10] Cruz, N., Briens, C., Berruti, F. "Supersonic attrition nozzles in gassolid fluidized beds." Chemical Engineering and Processing. 49(3), pp. 225-234. 2010. https://doi.org/10.1016/j.cep.2010.01.010

[11] Sau, C., Biswal, K. C. "Computational fluid dynamics and experimental study of the hydrodynamics of a gas-solid tapered fluidized bed." Applied Mathematical Modelling. 35(5), pp. 2265-2278. 2011. https://doi.org/10.1016/j.apm.2010.11.037
[12] Heinrich, S., Henneberg, M., Peglow, M., Drechsler, J., Mörl, L. "Fluidized bed spray granulation: analysis of heat and mass transfers and dynamic particle populations." Brazilian Journal of Chemical Engineering. 22(2), pp. 181-194. 2005. https://doi.org/10.1590/s0104-66322005000200004

[13] Ronsse, F. "Modelling heat and mass transfer in fluidized bed coating processes." Thesis submitted in fulfilment of the requirements for the degree of Doctor (PhD) in Applied Biological Sciences. Ghent University, Belgium. pp. 39-45. 2006. URL: https://biblio.ugent.be/ publication/470904/file/1878398.pdf

[14] Turton, R. "Challenges in the modeling and prediction of coating of pharmaceutical dosage forms." Powder Technology. 181(2), pp. 186194. 2006. https://doi.org/10.1016/j.powtec.2006.12.006

[15] Werner, S. R. L., Jones, J. R., Paterson, A. H. J. "Air suspension particle coating in the food industry: Part I- State of the art." Powder Technology. 171(1), pp. 25-33. 2007. https://doi.org/10.1016/j.powtec.2006.08.014

[16] Hemati, M., Cherif, R., Saleh, K., Pont, V. "Fluidized bed coating and granulation: Influence of process-related variables and physicochemical properties on the growth kinetics." Powder Technology. 130(1-3), pp. 18-34. 2003. https://doi.org/10.1016/s0032-5910(02)00221-8

[17] Vuppala, M. K., Parikh, D. M., Bhagat, H. R. "Application of powder-layering technology and film coating for manufacture of sustained release pellets using a rotary fluid bed processor." Drug Development and Industrial Pharmacy. 23(7), pp. 687-694. 1997.

https://doi.org/10.3109/03639049709150770

[18] Smith, P. G., Nienow, A. W. "Particle growth mechanisms in fluidized bed granulation. I. The effects of process variables." Chemical Engineering Science. 38(8), pp. 1223-1231. 1983. https://doi.org/10.1016/0009-2509(83)80042-6

[19] Saleh, K., Cherif, R., Hemati, M. "An experimental study of fluidized bed coating: Influence of operating conditions on growth rate and mechanism." Advanced Powder Technology. 10(3), pp. 255-277. 1999. https://doi.org/10.1163/156855299x00334

[20] Link, K. C., Schlünder, E. U. "Fluidized bed spray granulation. Investigation of the coating process on single sphere." Chemical Engineering and Processing: Process Intensification. 36(6), pp. 443457. 1997. https://doi.org/10.1016/s0255-2701(97)00022-6

[21] Smith, P. G., Nienow, A. W. "On atomizing a liquid into a gas-fluidized bed." Chemical Engineering Science. 37(6), pp. 950-954. 1982. https://doi.org/10.1016/0009-2509(82)80186-3

[22] Maronga, S. J., Wnukowski, P. "Establishing temperature and humidity profiles in fluidized bed coating." Powder Technology. 94(2), pp. 181185. 1997. https://doi.org/10.1016/s0032-5910(97)03353-6

[23] Maronga, S. J., Wnukowski, P. "The use of humidity and temperature profiles in optimizing the size of fluidized bed in a coating process." Chemical Engineering and Processing. 37(5), pp. 423-432. 1998. https://doi.org/10.1016/s0255-2701(98)00050-6

[24] Dewettinck, K., Huyghebaert, A. "Top-spray fluidized bed coating: Effect of process variables on coating efficiency." Food Science and Technology. 31(6), pp. 568-575. 1998. https://doi.org/10.1006/fstl.1998.0417

[25] Teunou, E., Poncelet, D. "Batch and continuous fluid bed coatingReview and state of the art." Journal of Food Engineering. 53(4), pp. 325-340. 2002. https://doi.org/10.1016/s0260-8774(01)00173-x

[26] Šibanc, R., Srčič, S., Dreu, R. "Numerical simulation of two-phase flow in a Wurster coating chamber and comparison with experimental results." Chemical Engineering Science. 99, pp. 225-237. 2013. https://doi.org/10.1016/j.ces.2013.05.057 
[27] Malone, K. F., Xu, B. H., Fairweather, M. "The combined-continuumand-discrete-model (CCDM) for simulation of liquid-particle flows." Computer Aided Chemical Engineering. 21, pp. 227-232. 2006. https://doi.org/10.1016/s1570-7946(06)80051-9

[28] Elghobashi, S. E., Abou-Arab, T. W. "A Two-Equation Turbulence Model for Two-Phase Flows." Physics of Fluids. 26(4), pp. 931-938. 1983. https://doi.org/10.1063/1.864243

[29] Gidaspow, D., Bezburuah, R., Ding, J. "Hydrodynamics of circulating fluidized beds: kinetic theory approach." Department of Chemical Engineering, Illinois Institute of Technology, Chicago, IL, USA. pp. 75-82. 1991. URL: http://www.osti.gov/scitech/servlets/purl/5896246

[30] Lun, C. K. K., Savage, S. B., Jeffrey, D. J., Chepurniy, N. "Kinetic Theories for Granular Flow: Inelastic Particles in Couette Flow and Slightly Inelastic Particles in a General Flow Field." Journal of Fluid Mechanics. 140(1), pp. 223-256. 1984.

https://doi.org/10.1017/s0022112084000586
[31] Douglas, J. F., Gasiorek J. M., Swaffield, J. A. "Fluid Mechanics." Longman Scientific and Technical. 1995.

[32] Piquet, J. "Turbulent Flows - Models and Physics." Springer Verlag. 1999.

[33] Marino, T. A. "Numerical analysis to study the effects of solid fuel particle characteristics on ignition, burning, and radiative emission." The George Washington University, Washington, DC, USA. pp. 51-55. 2008.

[34] Zank, J., Kind, M., Schlünder, E. U. "Particle growth and droplet deposition in fluidised bed granulation." Powder Technology. 120(1-2), pp. $76-81.2001$. https://doi.org/10.1016/s0032-5910(01)00350-3

[35] Schlichting, H., Gersten, K., Krause, E., Oertel, H., Mayes, C. "Boundary Layer Theory." 8th Ed., Springer-Verlag, Berlin. 2004. 